\title{
B-RAF Mutant Alleles Associated with Langerhans Cell Histiocytosis, a Granulomatous Pediatric Disease
}

\author{
Takeshi Satoh $^{19}$, Alexander Smith ${ }^{29}$, Aurelien Sarde ${ }^{19}$, Hui-chun Lu ${ }^{3}$, Sophie Mian ${ }^{2}$, Celine Trouillet ${ }^{1}$, \\ Ghulam Mufti ${ }^{2}$, Jean-Francois Emile ${ }^{4}$, Franca Fraternali ${ }^{3}$, Jean Donadieu ${ }^{5}$, Frederic Geissmann ${ }^{1 *}$
}

1 School of Medicine, Centre for Molecular and Cellular Biology of Inflammation (CMCBI), King's College London, London, United Kingdom, 2 Haematology Department, King's College London, London, United Kingdom, 3 Randall Division of Molecular Biophysics, King's College London, London, United Kingdom, 4 Hopital Ambroise-Pare, Pathology department, AP-HP, Paris, France, $\mathbf{5}$ Centre de Référence de I'Histiocytose, Hopital d'Enfants Armand Trousseau, Pediatric Hematology Unit, AP-HP, Paris, France

\begin{abstract}
Background: Langerhans cell histiocytosis (LCH) features inflammatory granuloma characterised by the presence of CD1a+ dendritic cells or 'LCH cells'. Badalian-Very et al. recently reported the presence of a canonical ${ }^{\mathrm{V} 600 \mathrm{E}} \mathrm{B}-\mathrm{RAF}$ mutation in $57 \%$ of paraffin-embedded biopsies from LCH granuloma. Here we confirm their findings and report the identification of two novel B-RAF mutations detected in LCH patients.

Methods and Results: Mutations of B-RAF were observed in granuloma samples from 11 out of 16 patients using 'next

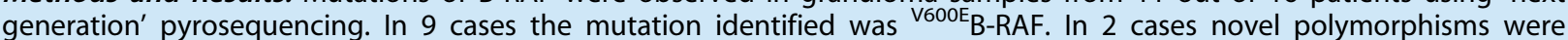
identified. A somatic ${ }^{600 D L A T} B-R A F$ insertion mimicked the structural and functional consequences of the ${ }^{{ }^{6}}{ }^{60 E} B-R A F$ mutant. It destabilized the inactive conformation of the B-RAF kinase and resulted in increased ERK activation in 293 T cells. The ${ }^{600 D L A T} B-R A F$ and ${ }^{\text {V600E }}$ B-RAF mutations were found enriched in DNA and mRNA from the CD1a+ fraction of granuloma. They were absent from the blood and monocytes of $58 \mathrm{LCH}$ patients, with a lower threshold of sequencing sensitivity of $1 \%-2 \%$ relative mutation abundance. A novel germ line ${ }^{T 599 A} B-R A F$ mutant allele was detected in one patient, at a relative mutation abundance close to $50 \%$ in the LCH granuloma, blood monocytes and lymphocytes. However, ${ }^{T 599 A}$ B-RAF did not destabilize the inactive conformation of the B-RAF kinase, and did not induce increased ERK phosphorylation or C-RAF transactivation.

Conclusions: Our data confirmed presence of the ${ }^{\mathrm{V} 600 \mathrm{E}} \mathrm{B}-\mathrm{RAF}$ mutation in LCH granuloma of some patients, and identify two novel B-RAF mutations. They indicate that ${ }^{\mathrm{V} 600 \mathrm{E}} \mathrm{B}-\mathrm{RAF}$ and ${ }^{600 \mathrm{DLAT}} \mathrm{B}-\mathrm{RAF}$ mutations are somatic mutants enriched in LCH $\mathrm{CD} 1 \mathrm{a}^{+}$cells and absent from the patient blood. Further studies are needed to assess the functional consequences of the germ-line ${ }^{\text {T599A } B-R A F}$ allele.
\end{abstract}

\footnotetext{
Citation: Satoh T, Smith A, Sarde A, Lu H-c, Mian S, et al. (2012) B-RAF Mutant Alleles Associated with Langerhans Cell Histiocytosis, a Granulomatous Pediatric Disease. PLoS ONE 7(4): e33891. doi:10.1371/journal.pone.0033891

Editor: Alice Y. W. Chang, Kaohsiung Chang Gung Memorial Hospital, Taiwan

Received October 20, 2011; Accepted February 19, 2012; Published April 10, 2012

Copyright: ( 2012 Satoh et al. This is an open-access article distributed under the terms of the Creative Commons Attribution License, which permits unrestricted use, distribution, and reproduction in any medium, provided the original author and source are credited.

Funding: TS is a fellow of the Japan Society for the Promotion of Science (JSPS) and FG is the Arthritis Research UK Chair of Inflammation Biology, at King's College London. This study was also funded by grants from the Histiocytosis Research Trust (HRT) and MRC G0900867 from the Medical Research Council (UK) to FG. The funders had no role in study design, data collection and analysis, decision to publish, or preparation of the manuscript.

Competing Interests: The authors have declared that no competing interests exist.

* E-mail: frederic.geissmann@kcl.ac.uk

9 These authors contributed equally to this work.
}

\section{Introduction}

Langerhans cell histiocytosis (LCH) is a pediatric granulomatous disease with an incidence of four to eight cases per million children $[1,2,3]$. The clinical spectrum of $\mathrm{LCH}$ is remarkably broad, ranging from isolated skin or bone lesions to a disseminated disease that may require aggressive chemotherapy $[1,4,5]$. LCH can lead to severe dental and periodontal lesions [6]. LCH also frequently leads to diabetes insipidus [1,2,3]. Apart from diabetes insipidus, central nervous system involvement in Langerhans cell histiocytosis $(\mathrm{LCH})$ is rare but represent a serious complication with neurological deterioration, including progressive cerebellar ataxia [7].

LCH lesions feature granulomatous collections of immature CDla+ langerin/CD207+ DG ('LCH cells') presumed to be pathologic $[8,9,10]$, admixed with abundant eosinophils [11], polyclonal $\mathrm{T}$ cells including abundant FoxP $3^{+} \mathrm{CD} 4^{+} \mathrm{T}$ cells [12], activated macrophages and osteoclast-like multinucleated giant cells [13]. These granuloma are therefore heterogeneous in cellular composition as well as anatomical distribution. The pathophysiology of LCH is largely unknown [10,14], although a genetic component is suggested by a higher concordance rate between monozygotic twins compared with dizygotic twins [15]. The tropism of skin lesions to flexures also suggests that external stimuli may trigger inflammation [16]. However, the nature of the initiating event(s), and the mechanisms of local tissue destruction by LCH and other inflammatory cells are still largely unknown.

Clonality of LCH granulomas has been reported in 1994 $[17,18]$. Its significance remained controversial, since specific genetic abnormalities were not consistently observed [19], until recently. Progress came from the identification by Badalian-Very 
et al., of a ${ }^{\mathrm{V} 600 \mathrm{E}} \mathrm{B}-\mathrm{RAF}$ mutation by pyrosequencing of formalinfixed, paraffin-embedded material, from 35 out of 61 archived specimens (57\%) [20]. This ${ }^{\mathrm{V} 600 \mathrm{E}} \mathrm{B}-\mathrm{RAF}$ mutation is likely to be somatic, because a germ-line activating ${ }^{\mathrm{V} 600 \mathrm{E}} \mathrm{B}-\mathrm{RAF}$ allele is embryonic lethal in mice [21]. B-RAF is a protein kinase activated by ras-coupled receptor tyrosine kinases (RTK) that is central to signaling via the Mitogen Activated Kinase (MAPK) and phosphorylates its downstream target MEK and ERK kinases [22]. The RAS-RAF-MAPK pathway coordinates a large variety of cellular responses involved in development, cell cycle regulation, cell proliferation and differentiation, cell survival and apoptosis, and many other physiological processes, by transmitting extracellular signals to various nuclear, cytoplasmic and membrane-bound targets [22].

Data obtained from murine model using Cre-mediated activation of a conditionnal B-RAF allele indicate that ${ }^{\mathrm{V} 600 \mathrm{E}} \mathrm{B}-$ RAF can contribute to tumour initiation [23]. For example, ${ }^{\mathrm{V} 600 \mathrm{E}} \mathrm{B}-\mathrm{RAF}$ induces high levels of cyclin Dl-mediated cell proliferation. However, ${ }^{\mathrm{V} 600 \mathrm{E}} \mathrm{B}-\mathrm{RAF}$ also induces oncogeneinduced senescence (OIS) that may restrain further development of the tumour [23,24]. In human, somatic ${ }^{\mathrm{V} 600 \mathrm{E}} \mathrm{B}-\mathrm{RAF}$ mutation have been found in a number of benign and malignant tumors including non-malignant naevi [25], melanoma [26], colon and thyroid tumors $[21,22,24,26]$. Thus ${ }^{\mathrm{V} 600 \mathrm{E}} \mathrm{B}-\mathrm{RAF}$ may represent a first step toward the development of a malignant tumor, although the presence of a ${ }^{\mathrm{V} 600 \mathrm{E}} \mathrm{B}-\mathrm{RAF}$ mutation is not synonymous with cancer.

Of note, the clinical features of LCH are not typical of cancer $[10,14]$ and LCH lesions frequently regress, either spontaneously or after local treatment $[1,4,5]$. In addition, LCH CDla+ cells, which are presumed to be pathologic, very slowly proliferate in most patients [12], while the expansion of a monocyte or dendritic cell compartment, which represent candidate precursors for these $\mathrm{CDla}$ cells of the granuloma, was not consistently observed in the blood of LCH patients [12,27].

Identification of dysregulation of the RAS-RAF-MAPK pathway in LCH is nevertheless an important step towards a molecular understanding of the pathophysiology of this pediatric granuloma. It suggests possible novel therapeutic approaches, e.g. the use of BRAF or MEK inhibitors. Moreover, if ${ }^{\mathrm{V} 600 \mathrm{E}} \mathrm{B}-\mathrm{RAF}$ was detectable in the patient's blood, this could be of use for diagnostic, monitoring of treatment efficacy, and potentially prognostic purposes.

We therefore sought firstly to confirm the finding of BadalianVery using another methodology i.e. analyzing flow sorted CDla+ cells from fresh LCH granuloma tissue instead of paraffin embedded biopsies. We then aimed to compare relative mutation abundance of V600E B-RAF mutations between CDlat and CDla - cells from LCH granuloma, and whether mutations can be detected in the peripheral blood of patients. Finally we investigated whether additional B-RAF mutations can be found in $\mathrm{LCH}$ patients, to further reinforce the link between $\mathrm{LCH}$ and the RAS-RAF pathway.

\section{Results}

\section{B-RAF polymorphisms associated with $\mathrm{LCH}$}

We investigated the presence of B-RAF mutations by 'next generation' pyrosequencing (Roche GS FLX 454) in a series of 16 granuloma samples obtained at diagnosis from 16 patients with LCH from a cohort followed in the French LCH Registry (Tables 1 \& 2). Among granuloma samples $11 / 16$ carried B-RAF mutations as detected by pyrosequencing of granuloma genomic DNA (gDNA) and cDNA (Table 1). In 9/11 cases (patients \#1-9) we found a g1799 $\mathrm{T}>\mathrm{A}$ transition resulting in the previously described ${ }^{\mathrm{V} 600 \mathrm{E}} \mathrm{B}-\mathrm{RAF}$ mutation [20] (Figure $1 \mathrm{~A}$ ). In one patient (patient \#10) we found a novel in-frame insertion of 12 nucleotides, leading to the insertion of 4 amino acids (Asp-LeuAla-Thr, or DLAT) (Figure $1 \mathrm{~A}$ ). In one other patient we observed an $\mathrm{A}>\mathrm{G}$ transversion, producing a ${ }^{\mathrm{T} 599 \mathrm{~A}} \mathrm{~B}-\mathrm{RAF}$ allele (Table 2, Figure $1 \mathrm{~A})$. The ${ }^{\mathrm{T} 599 \mathrm{~A}} \mathrm{~B}-\mathrm{RAF}$ and ${ }^{600 \mathrm{DLAT}} \mathrm{B}-\mathrm{RAF}$ alleles were not previously reported in the literature, dbSNP (v131), or in data from 1000 genomes project (Nov 10 release).

\section{Somatic B-RAF mutations}

The ${ }^{\mathrm{V} 600 \mathrm{E}} \mathrm{B}-\mathrm{RAF}$ and ${ }^{600 \mathrm{DLAT}} \mathrm{B}-\mathrm{RAF}$, mutations were detected in granuloma from patients $1-10$ with a high relative mutation abundance (RMA) (Table 2) We therefore investigated whether these alleles were germ-line or somatic mutants, and which cellular fraction of the granuloma was bearing the mutation. In 4 cases of ${ }^{\mathrm{V} 600 \mathrm{E}} \mathrm{B}-\mathrm{RAF}$ mutation (Patients 4, 5, 8, 9) and in the sample carrying the ${ }^{600 \mathrm{DLAT}} \mathrm{B}-\mathrm{RAF}$ mutation (patient \#10) (Table 2), CDlat cells were enriched from fresh granuloma tissue using antibody-coupled beads [8]. The CDla-depleted fractions (Effluent, Table 2) were also collected in 4 cases (Patients 5, 8, 9, 10, Table 2). Genomic DNA and cDNA were extracted from all samples and analysed by next generation sequencing. In all cases $\mathrm{B}-\mathrm{RAF}$ mutated alleles were enriched in the CDla+ fraction at the genomic DNA and cDNA level, in comparison with the CDladepleted fractions, with a relative mutation abundance of up to $48 \%$ (Table 2), suggesting that the CDla+ 'LCH cells' carry a heterozygous B-RAF mutant allele, though we did not assess heterozygosity at the single cell level. We then investigated whether ${ }^{V 600 E}$ B-RAF or ${ }^{600 D L A T}$ B-RAF mutations could be found in the patients circulating myeloid or lymphoid cells, either because of a germ-line mutation, or because of a mosaicism in bone marrow progenitors. Analysis by pyrosequencing of whole blood and of purified monocytes (CD14+) and lymphocytes (CD14-) from patient 1 indicated the absence of detectable BRAF mutations, with a lower threshold of sequencing sensitivity of $1 \%-2 \%$ relative mutation abundance. Analysis of whole blood from patient 2 with the same method also failed to detect a ${ }^{\mathrm{V} 600 \mathrm{E}} \mathrm{B}$ RAF mutation. Blood samples were not available for the 8 other patients with a ${ }^{\mathrm{V} 600 \mathrm{E}} \mathrm{B}-\mathrm{RAF}$ or ${ }^{600 \mathrm{DLAT}} \mathrm{B}-\mathrm{RAF}$ mutation.

We therefore investigated the presence of B-RAF mutations in peripheral blood mononuclear cells of an additional series of LCH patients for whom blood samples were available either at diagnosis or relapse $(n=22)$ (Table 3), or under treatment $(n=32)$. Neither ${ }^{\mathrm{V} 600 \mathrm{E}} \mathrm{B}-\mathrm{RAF}$ or ${ }^{600 \mathrm{DLAT}} \mathrm{B}-\mathrm{RAF}$ were detectable by pyrosequencing in these 56 peripheral blood mononuclear cell samples (Tables $2 \&$ 3 , and data not shown). Unfortunately granuloma samples were not availables for these patients, however based on the frequency of B-RAF mutation in LCH granuloma, $57 \%$ in the BadalianVery study, and $11 / 16(68 \%)$ in the present study, it is likely that several of the 56 patients had a B-RAF mutation in their granuloma.

In aggregate, these data indicate that ${ }^{\mathrm{V} 600 \mathrm{E}} \mathrm{B}-\mathrm{RAF}$ and ${ }_{600 D L A T}$ B-RAF mutations are detectable in granuloma but not in the blood, and thus strongly suggest they are somatic events. In addition, lack of detection of B-RAF mutations in the blood from patients 1 and 2 and from the 22 others patients for whom blood samples were available at diagnosis or relapse suggests that detection of potential circulating B-RAF mutated cells will require a threshold of sensitivity below $1 \%$.

\section{Germline B-RAF polymorphisms}

In contrast, the ${ }^{\mathrm{T} 599 \mathrm{~A}} \mathrm{~B}-\mathrm{RAF}$ mutation was detected in both the granuloma and the whole blood of patient \#16. ${ }^{\text {T599A B-RAF was }}$ 
Table 2. Presence and relative abundance of B-RAF mutant clones identified in granuloma and blood from patients with LCH.

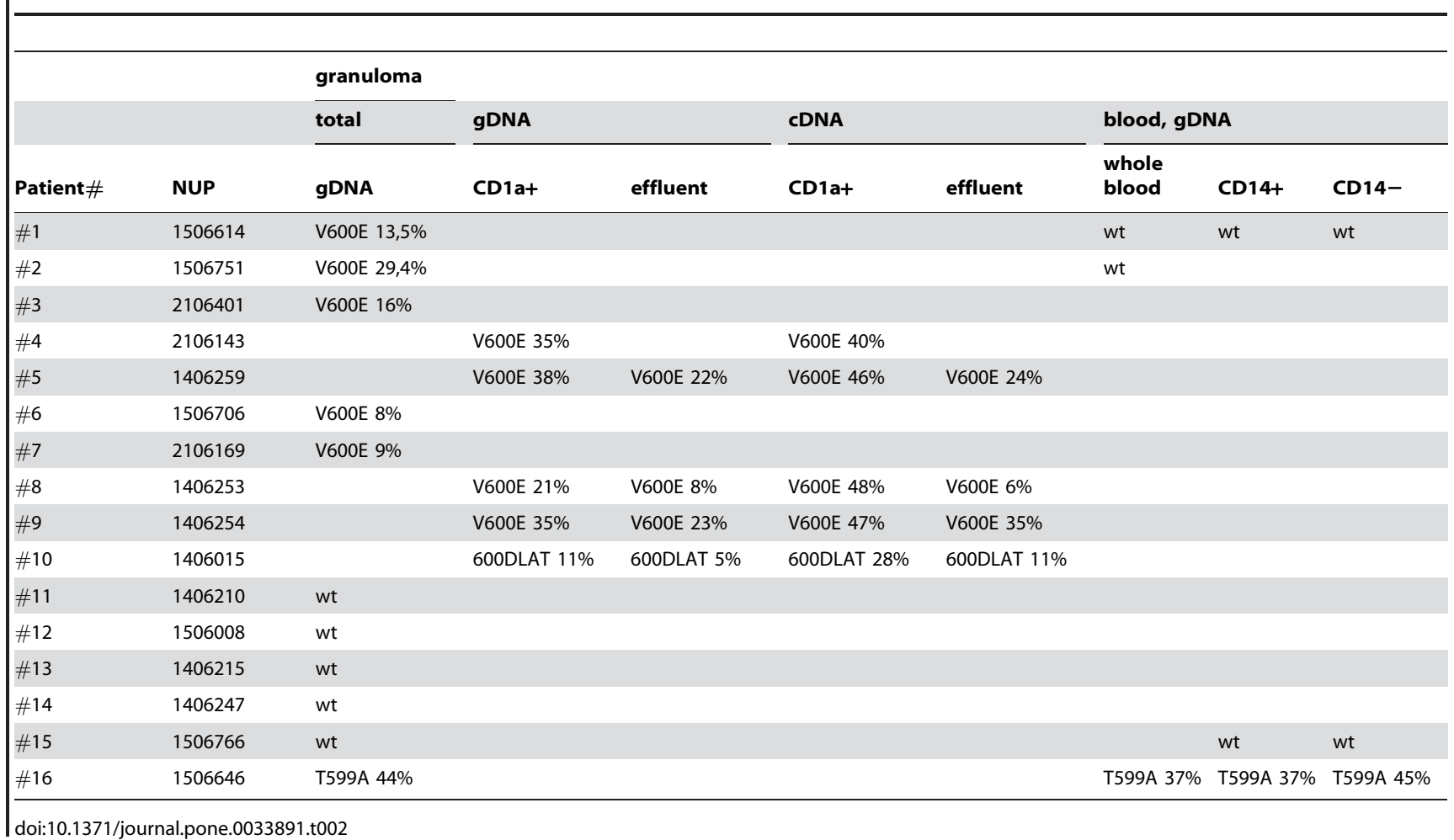

detected in the monocytic (CD14+) and lymphoid fractions (CD14-), at a high frequency of 37 to $45 \%$ relative mutation abundance, respectively, similar to its abundance in the granuloma (Table 2). This pattern suggested a germ-line mutation. Conventional 'Sanger' sequencing of peripheral blood mononuclear cells from the patient and from the patient's mother with an Applied Biosystem Genetic analyzer 3730xl confirmed the presence of an allelic mutation (Figure 1 B). Therefore the ${ }^{\mathrm{T} 599 \mathrm{~A}} \mathrm{~B}-\mathrm{RAF}$ mutation was present in the peripheral blood of the patient and his mother, indicating a germ-line transmitted allele (Figure $1 \mathrm{C}$ ).

Altogether, these data indicate that ${ }^{\mathrm{V} 600 \mathrm{E}} \mathrm{B}-\mathrm{RAF}$ and ${ }^{600 \mathrm{DLAT}} \mathrm{B}-$ RAF are somatic events while ${ }^{\mathrm{T} 599 \mathrm{~A}} \mathrm{~B}-\mathrm{RAF}$ is a germ-line polymorphism.

\section{B-RAF 600DLAT is an activating B-RAF mutant}

Substitution of Val600 with Glu $\left({ }^{\mathrm{V} 600 \mathrm{E}} \mathrm{B}-\mathrm{RAF}\right)$ strongly activates B-RAF [28,29]. ${ }^{600 D L A T} \mathrm{~B}-\mathrm{RAF}$ is an in-frame insertion of 12 nucleotides leading to the insertion of 4 amino acids (Asp-Leu-AlaThr, or DLAT) starting from position 600 (Figure 1 A). This insertion, in the structural alignment superimposed to the V600 position, therefore effectively results in a B-RAFV600D substitution, leaving the insertion constituted only by a LATV segment. We have examined the residues surrounding D600 in the structure within a cut-off range of $6 \AA$. As reported by Wan et al. [29] the V600 residue is in a cluster of hydrophobic residues with Phe468, therefore the presence of a negative charge (residue D) will disrupt this cluster, resulting in destabilization of the inactive conformation of ${ }^{600 \mathrm{DLAT}} \mathrm{B}-\mathrm{RAF}$, exactly as for the V600E mutant (Figure 1 D-F). As expected from our structural modelisation study, ${ }_{600 \mathrm{DLAT}} \mathrm{B}-\mathrm{RAF}$ resulted in increased MEK and ERK activation upon transient transfection in $293 \mathrm{~T}$ cells in comparison to wildtype B-RAF, similar to what is observed for ${ }^{\mathrm{V} 600 \mathrm{E}} \mathrm{B}-\mathrm{RAF}$ [29] (Figure 1). However, we could not investigate the role of ${ }^{\mathrm{V} 600 \mathrm{E}} \mathrm{B}$ RAF and ${ }^{600 D L A T}$ B-RAF in myeloid cells, since, when transfected in U937 and THP1 myeloid cell lines both ${ }^{\mathrm{V} 600 \mathrm{E}} \mathrm{B}-\mathrm{RAF}$ and ${ }_{600 \mathrm{DLAT}} \mathrm{B}-\mathrm{RAF}$ resulted in growth arrest and cell death (data not shown).

\section{B-RAF T599A is a dead-kinase B-RAF mutant that does not transactivate C-RAF}

Thr599 is a major phosphorylation site in the B-RAF activation domain [28], and substitution of Thr599 with alanine was shown in vitro to suppress B-RAF activity. Indeed, in contrast to ${ }^{\mathrm{V} 600 \mathrm{E}} \mathrm{B}$ RAF and ${ }^{600 D L A T} \mathrm{~B}-\mathrm{RAF},{ }^{\mathrm{T} 599 \mathrm{~A}} \mathrm{~B}-\mathrm{RAF}$ substitutes a polar uncharged residue with a hydrophobic residue, causing the loss of short-ranged interactions with residues D576 and D594 (Figure $1 \mathrm{~A}, \mathrm{~B}$ ). This does not predict a destabilization of the inactive conformation of B-RAF. Indeed transfection of ${ }^{\mathrm{T} 599 \mathrm{~A}} \mathrm{~B}$ RAF in $293 \mathrm{~T}$ cells did not increase MEK and ERK phosphorylation, in comparison to wt control (Figure $1 \mathrm{G}$ ). Co-transfection of $\mathrm{C}-\mathrm{RAF}$ did not increase MEK and ERK phosphorylation in the presence of ${ }^{\text {T599A }}$ B-RAF (Figure $1 \mathrm{H}$ ). To further investigate the function of ${ }^{\mathrm{T} 599 \mathrm{~A}} \mathrm{~B}-\mathrm{RAF}$ in myeloid cells, we retrovirally transfected ${ }^{\mathrm{wt}} \mathrm{B}-\mathrm{RAF}$ and ${ }^{\mathrm{T} 599 \mathrm{~A}} \mathrm{~B}-\mathrm{RAF}$ in $\mathrm{THP} 1$ myeloid cells. As shown in Figure $2 \mathrm{C}$ and $2 \mathrm{D}{ }^{\mathrm{T} 599 \mathrm{~A}} \mathrm{~B}-\mathrm{RAF}$ did not induce MEK and ERK phosphorylation in THPl cells above control (Figure $2 \mathrm{C}$ ). Thus ${ }^{\mathrm{T} 599 \mathrm{~B}} \mathrm{~B}-\mathrm{RAF}$ may represent a mutant devoid of intrinsic kinase activity.

However, some B-RAF mutants found in cancer such as ${ }^{\mathrm{D} 594 \mathrm{~A}} \mathrm{~B}-\mathrm{RAF}$, albeit devoid of intrinsic B-RAF kinase activity, can transactivate $\mathrm{C}-\mathrm{RAF}$ and the MEK/ERK pathway [30,31]. We thus compared the activity of ${ }^{\mathrm{T} 599 \mathrm{~A}} \mathrm{~B}-\mathrm{RAF}$ with that of ${ }^{\mathrm{wt}} \mathrm{B}-\mathrm{RAF}$ and ${ }^{\mathrm{D} 594 \mathrm{~A}} \mathrm{~B}-\mathrm{RAF}$ after retroviral transfection into U937 cells. Results indicated that unlike ${ }^{\mathrm{D} 594 \mathrm{~A}} \mathrm{~B}-\mathrm{RAF},{ }^{\mathrm{T} 599 \mathrm{~A}} \mathrm{~B}-\mathrm{RAF}$ did not induce MEK/ERK phosphorylation (Figure 2 D, E) or IL-8 production (Figure $2 \mathrm{~F}$ ) by U937 cells. 
Table 3. Age, sex, clinical features, and molecular findings in 22 patients with available blood samples at the time of diagnosis or relapse.

\begin{tabular}{|c|c|c|c|c|c|c|}
\hline \multirow[t]{2}{*}{ patient \# } & \multirow[t]{2}{*}{ NUP } & \multirow[t]{2}{*}{ Clinical features } & \multirow[t]{2}{*}{ status at the time of blood sample } & \multirow{2}{*}{$\begin{array}{l}\text { BRAF } \\
\text { whole blood }\end{array}$} & \multirow[b]{2}{*}{ CD14+ } & \multirow[b]{2}{*}{ CD14- } \\
\hline & & & & & & \\
\hline \#17 & 1406220 & bone skin, ENT, pituitary, neuro & active/progressive disease & na & wt & wt \\
\hline \#18 & 1506752 & skin & active/progressive disease & wt & na & na \\
\hline \#19 & 1506604 & Bone, skin, hematological dysfunction & active/progressive disease & wt & na & na \\
\hline \#20 & 1506648 & $\begin{array}{l}\text { Bone, skin, ENT, lung, liver, } \\
\text { hematological dysfunction }\end{array}$ & active/progressive disease & wt & na & na \\
\hline \#21 & 1506882 & Skin, ENT & active/progressive disease & wt & na & na \\
\hline \#22 & 1506863 & $\begin{array}{l}\text { Bone, skin, ENT, lung, liver, } \\
\text { hematological dysfunction }\end{array}$ & active/progressive disease & wt & na & na \\
\hline \#23 & 1506009 & $\begin{array}{l}\text { Bone, skin, ENT, nodes, pituitary, lung, } \\
\text { liver, spleen, hematological dysfunction }\end{array}$ & active/progressive disease & wt & na & na \\
\hline \#24 & 1507109 & skin, ENT, pituitary & active/progressive disease & wt & na & na \\
\hline \#25 & 2106005 & Bone, skin, ENT, CNS mass lesion & active/progressive disease & wt & na & na \\
\hline \#26 & 1509003 & bone & at diagnosis, before treatment & wt & na & na \\
\hline \#27 & 1506819 & bone & at diagnosis, before treatment & wt & na & na \\
\hline \#28 & 1507093 & bone & at diagnosis, before treatment & wt & wt & na \\
\hline \#29 & 1506957 & lung & at diagnosis, before treatment & wt & na & na \\
\hline \#30 & 1506973 & bone, pituitary & at diagnosis, before treatment & wt & na & na \\
\hline \#31 & 1507062 & Skin & at diagnosis, before treatment & wt & wt & wt \\
\hline \#32 & 1506869 & bone & 1 MONTH DIAGNOSIS & wt & na & na \\
\hline \#33 & 1507096 & bone & <2 MONTH DIAGNOSIS & na & wt & wt \\
\hline \#34 & 1506754 & skin & 2 MONTHS DIAGNOSIS & wt & na & na \\
\hline \#35 & 1506865 & bone & 2 MONTH DIAGNOSIS & wt & na & na \\
\hline \#36 & 1507084 & skin & 2 MONTH DIAGNOSIS & wt & wt & wt \\
\hline \#37 & 1506932 & bone & 3 MONTH DIAGNOSIS & wt & wt & na \\
\hline \#38 & 1506984 & skin & 3 MONTH DIAGNOSIS & wt & na & na \\
\hline
\end{tabular}

doi:10.1371/journal.pone.0033891.t003

\section{Clinical features of patients with B-RAF mutations}

${ }^{\mathrm{V} 600 \mathrm{E}} \mathrm{B}-\mathrm{RAF}$ mutations were found both in children with granuloma of bones or isolated skin disease, and in infants with early-onset multi-organ disease (Table 1). Among the 16 studied patients, we compared the proportion of patients with or without B-RAF mutations according to the extension of the disease by Fisher exact test and according to the age of diagnosis by Kruskall Wallis Test. No significant difference was observed as the $\mathrm{p}$ value was above 0.05 for all tests. However the sample size was small and may not be representative of a population based sample of patients. The patient with a ${ }^{600 D L A T} \mathrm{~B}-\mathrm{RAF}$ insertion presented with early-onset multi-organ disease, but responded well to treatment (Patient \#10, Table 1). The patient with a germ-line ${ }^{\text {T599A }} \mathrm{B}-\mathrm{RAF}$ allele (Patient \#16, Table 1) presented at the age of 10 months with persistent swelling of the left parietal bone. Two months after, clinical examination revealed 10 small skin nodules. Biopsy of one skin element demonstrated the histological diagnosis of LCH with the presence of CDla+ cells. Patient \#16 received therapy by vinblastine and steroid, as per the LCH III protocol, for a total duration of one year. No reactivation of the disease or sequellae was observed during a 7year follow-up. His mother, who carried the same allelic mutation, is in good health and did not report a personal history of LCH.

\section{Discussion}

In this study we confirm the findings by Badalian-Very et al. [20], that ${ }^{\mathrm{V} 600 \mathrm{E}} \mathrm{B}-\mathrm{RAF}$ mutations are detected in $\mathrm{LCH}$ granuloma, and identify two additional mutations ${ }^{600 D L A T} \mathrm{~B}-\mathrm{RAF}$ and ${ }^{\mathrm{T} 599 \mathrm{~A}} \mathrm{~B}$ RAF in two LCH patients. The ${ }^{600 D L A T}$ B-RAF mutants mimics ${ }^{\mathrm{V} 600 \mathrm{E}} \mathrm{B}-\mathrm{RAF}$ at the structural and functional level. Our results also indicate that ${ }^{\mathrm{V} 600 \mathrm{E}} \mathrm{B}-\mathrm{RAF}$ and ${ }^{600 \mathrm{DLAT}} \mathrm{B}-\mathrm{RAF}$ mutations are enriched in CDlat 'LCH' granuloma cells and absent from the blood of 58 patients, suggesting the presence of somatic mutations in CDla+ cells, and arguing against a mosaicism in the myeloid lineage or a bone marrow clonal disease, within the sensitivity limits of our deep-sequencing assay. We also identified a novel germ-line ${ }^{\mathrm{T} 599 \mathrm{~A}} \mathrm{~B}-\mathrm{RAF}$ polymorphism in a patient with $\mathrm{LCH}$, although it remains unclear whether ${ }^{\mathrm{T} 599 \mathrm{~A}} \mathrm{~B}-\mathrm{RAF}$ is involved in the pathophysiology of $\mathrm{LCH}$ in this patient. The data presented here strengthen the association between B-RAF mutation and a dysregulation of the RAS-RAF-MEK pathway in CDla+ LCH cells from LCH granuloma.

Both the study by Badalian-Very [20] and our present report fail to show a correlation between the presence of B-RAF mutations in LCH granuloma and the patient's age, clinical presentation, or outcome. However, the total number of cases analysed reported (77 in total) is still too small to allow a powerful 
A

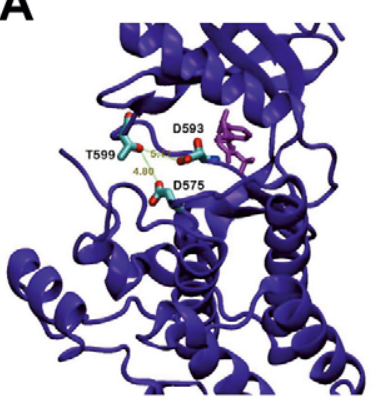

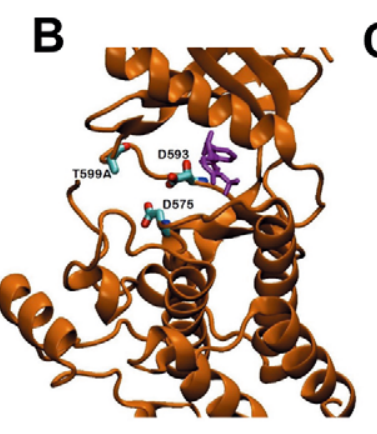

C
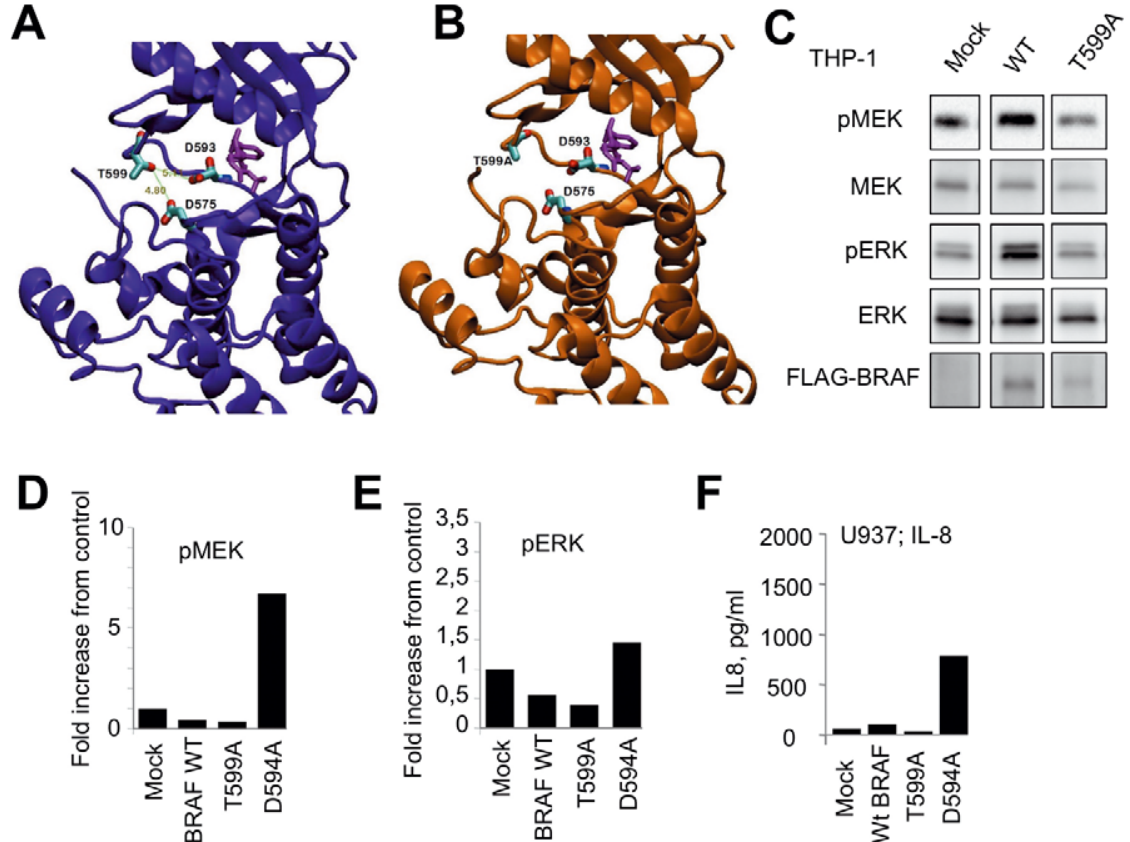

E
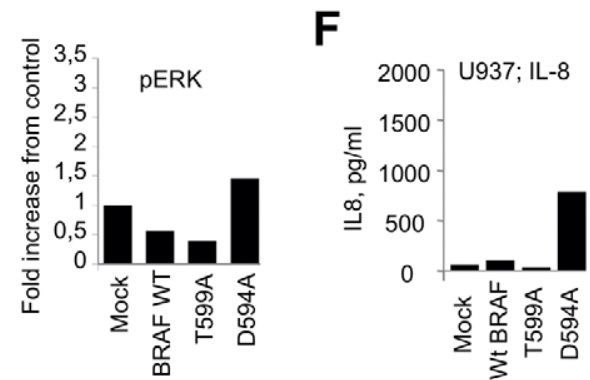

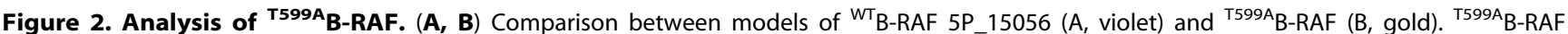
substitutes a polar uncharged residue with a hydrophobic residue, causing the loss of short-ranged interactions with residues D576 and D594. C. Analysis of MEK and ERK phosphorylation in THP1 cell lines stably transfected with ${ }^{\text {WT }}$ B-RAF-FLAG and ${ }^{\text {T599A }}$ B-RAF-FLAG. Experiment was repeated twice with similar results. (D-F) Analysis of MEK and ERK phosphorylation and IL-8 production in U937 cell lines stably transfected with ${ }^{\text {WT }}$ B-RAF, ${ }_{T 599 A}$ B-RAF, and ${ }^{D 594 A}$ B-RAF. Experiment was repeated twice with similar results.

doi:10.1371/journal.pone.0033891.g002

statistical analysis, given the marked clinical heterogeneity of the disease $[1,4,5]$. A statistical study of the possible association or lack of association of B-RAF somatic mutations with subgroups of $\mathrm{LCH}$ patients or with the natural history of the disease remains to be done, in a population based approach.

Our results indicate that both ${ }^{600 \mathrm{DLAT}} \mathrm{B}-\mathrm{RAF}$ and ${ }^{\mathrm{V} 600 \mathrm{E}} \mathrm{B}-\mathrm{RAF}$ mutations are somatic events which are not detected in the blood of patients. LCH granulomas may thus arise from a local process within affected tissues, rather than from the continuous recruitment of putative precursors, such as monocytes or dendritic cells carrying activating B-RAFV600E or B-RAF600DLAT alleles. Nevertheless, given the threshold sensitivity of $1 \%-2 \%$ of our deep-sequencing method, we cannot exclude the contribution of a minor myeloid-restricted clone in the bone marrow of patients, or of a subset of patients, and a prospective investigation is required to further investigate whether detection of rare circulating or bone marrow B-RAF mutated cells may be useful to monitor residual disease.

While substitution of Val600 with Glu ( $\left.{ }^{\mathrm{V} 600 \mathrm{E}} \mathrm{B}-\mathrm{RAF}\right)$ strongly activates B-RAF, substitution of Thr599 with Ala ( ${ }^{\text {T599A }}$ B-RAF) impairs B-RAF kinase activity [28,29] given that Thr599 is the major phosphorylation site in the B-RAF activation domain [28]. Other mutations that affect intrinsic B-RAF kinase activity such as ${ }^{\mathrm{D} 594 \mathrm{~A}} \mathrm{~B}-\mathrm{RAF}$ can also transactivate C-RAF and the MEK/ERK pathway, albeit less strongly [30,31]. However we have shown here that ${ }^{\mathrm{T} 99 \mathrm{~A}} \mathrm{~B}-\mathrm{RAF}$ was both impaired in its intrinsic B-RAF kinase activity and unable to transactivate C-RAF. At this time, we do not have a molecular explanation for this observation. Further studies will therefore be needed to potentially unveil the functional consequences of the ${ }^{\mathrm{T} 599 \mathrm{~A}} \mathrm{~B}-\mathrm{RAF}$ allele on cell activation. The patient's mother born in 1977 carried the same B-RAFT599A allele while in good health, and without a personal history of LCH. Therefore, although the ${ }^{\mathrm{T} 599 \mathrm{~A}} \mathrm{~B}-\mathrm{RAF}$ allele is not a common polymorphism, there is no evidence that ${ }^{\mathrm{T} 599 \mathrm{~A}} \mathrm{~B}-\mathrm{RAF}$ is involved in the pathophysiology of LCH in our patient. However the clinical spectrum of LCH is remarkably broad, and the age of onset highly variable $[1,4,5]$, preventing us to definitely conclude to the absence of LCH in the mother of the patient. For instance, in one previously reported case of familial LCH, a monostotic lesion was diagnosed in a 20-year-old woman and then also in her daughter when aged 30 months [32].

Finally, ${ }^{\mathrm{V} 600 \mathrm{E}} \mathrm{B}-\mathrm{RAF}$ mutations are observed in a number of benign and tumoral diseases (e.g. naevi and melanoma [25,26]). In itself this mutation thus do not characterize a malignant disease. It is posssible that the effects of activating B-RAF mutations such as ${ }^{\mathrm{V} 600 \mathrm{E}} \mathrm{B}-\mathrm{RAF}$ and ${ }^{600 \mathrm{DLAT}} \mathrm{B}-\mathrm{RAF}$ are different whenever they occur in stem cells or and differentiated cells, and depending on the lineage of the mutated cells, i.e. epithelial or myeloid. Therefore, more work is needed to understand the consequences of ${ }^{\mathrm{V} 600 \mathrm{E}}$ B-RAF and ${ }^{600 \mathrm{DLAT}}$ B-RAF in myeloid cells. We observed that retroviral transduction of either ${ }^{\mathrm{V} 600 \mathrm{E}} \mathrm{B}-\mathrm{RAF}$ or ${ }^{600 \mathrm{DLAT}} \mathrm{B}-$ RAF in U937 and THP1 myeloid cell lines resulted in growth arrest and cell death. This suggests that an in vivo approach may be preferable, since an appropriate cellular environment could be required to support cell growth of ${ }^{\mathrm{V} 600 \mathrm{E}} \mathrm{B}-\mathrm{RAF}$ or ${ }^{600 \mathrm{DLAT}} \mathrm{B}-\mathrm{RAF}$ expressing myeloid cells. In this regard, mouse models of conditional expression of B-RAF mutant alleles in different cell lineages [23], should prove extremely useful.

\section{Materials and Methods}

\section{Patients}

Patients were registered in the National French Registry for Langerhans Cell Histiocytosis. LCH diagnosis was established on the basis of the patients' clinical history, histological examination and the mandatory presence of CDlat histiocytes in clinical 
biopsy specimens, and reviewed by a national panel of pathologists. Patient's parents gave written informed consent for the study. The Study was approved by the Institutional Review Board of the University Hospital of Nantes, France. Characteristic of patients 1-16 are summarized in Table 1. Biopsies samples and/or blood were obtained at diagnosis from 15 patients with various clinical forms of the disease, isolated involvement of bone $(n=9)$, early-onset multisystem disease $(n=4)$, isolated skin $(n=1)$ and skin and lung disease $(n=1)$ (Table 1). Purified CDla+ cells were isolated from biopsies from patients with eosinophilic granuloma of bone $(\mathrm{n}=3)$ and early-onset multisystem disease $(\mathrm{n}=3)$. Blood was obtain from patient 16 and his parents, and epithelial cells from patient 16 , his parents and brother.

\section{Preparation of DNA from granuloma samples, whole blood, and purified cellular fractions}

Samples from CDla+ LCH cells were obtained as previously described [8]. In brief, after frozen section examination, sterile tissue from eosinophilic granuloma was harvested in RPMI 1640 supplemented with $2 \mathrm{mM}$ L-glutamine, $100 \mathrm{U} / \mathrm{mL}$ penicillin, $100 \mu \mathrm{g} / \mathrm{mL}$ streptomycin, and $10 \%$ heat-inactivated fetal calf serum (FCS) myoclone (all from GIBCO BRL, Gaithersburg, $\mathrm{MD})$, referred to below as complete medium. Tissues were immediately gently dissociated through a nylon mesh. The cell suspension was washed 3 times and incubated with human IgG to block Fc receptor, and anti-CDla antibody (BL6; Immunotech, Marseille, France). The cells were washed twice, incubated with antimouse microbeads (MACS; Miltenyi Biotec, Bergisch Gladbach, Germany) for 15 minutes at $4^{\circ} \mathrm{C}$. Cells were washed again, and then CDlat LCH cells were separated by positive immunomagnetic selection by using a magnetic cell separator (MACS) according to the manufacturer's instructions. Between 2.105 and $6.105 \mathrm{CDla}+$ cells were recovered from each sample. Purity of CDlat and CDlalow/neg sorted fraction was $80 \%$ or greater and mortality $10 \%$ or less. Genomic DNA and RNA from frozen granuloma cells, sorted CDla+ cells and effluent fractions lysed and stored in Trizol were extracted using chloroform, the organic phase was transferred to a fresh tube to extract genomic DNA, and RNA was extracted using the RNA microkit from Qiagen. cDNA was obtained using the Superscript III Reversetranscriptase kit (Invitrogen) according to the manufacturer's procedure. Genomic DNA extraction from paraffin sections (Patient 16) was performed as per Qiagen protocol for this material. Genomic DNA extraction from whole Blood was performed using the GenElute Blood genomic DNA kit mini prep from Sigma Aldrich according to the manufacturer procedure. Peripheral blood mononuclear cells (PBMCs) were obtained by the standard Ficoll-Hypaque method. CD14+ and CD14- fraction were separated by negative magnetic depletion by using haptenconjugated CD3, CD7, CD19, CD45RA, CD56, and anti-IgE antibodies (MACS; Miltenyi Biotec) and a MACS according to the manufacturer's instructions. gDNA and RNA were extracted from CD14+ and CD14- MACS purificated monocytes fractions using the RNA/DNA AllPrep QIAgen Minikit (Quiagen).

\section{B-RAF mutation detection}

Pyrosequencing assay was performed using with 454 sequencing (Roche GS FLX platform). Primers sets were designed to amplify B-RAF exons 11 and 15 from both genomic DNA and cDNA, which incorporated a universal forward and reverse sequence tag. A second round of PCR was also performed utilizing the universal tags, to incorporate a sample specific $10 \mathrm{bp}$ "barcode" sequence as well as additional tags utilized in the sequencing process (Roche GS FLX Titanium). Sequencing was performed to yield a 'depth' in excess of 500 clonal reads $(500 \times)$ per exonic amplicon, per patient sample in most cases. This allowed detection of mutant clones down to around $1-2 \%$ relative mutation abundance, defined as the proportion of sequence reads that contain the mutation. Independent PCR and GS FLX sequencing experiments were carried out to confirm mutations and to reduce sampling error for calculations of mutation abundance. Somatic mutation in patient \#16, his parents and his sibling were confirmed using a Applied Biosystem Genetic analyzer 3730xl (primers available on request).

\section{B-RAF mutation modeling}

The B-RAF patient mutations ${ }^{600 \mathrm{DLAT}} \mathrm{B}-\mathrm{RAF}$ and ${ }^{\mathrm{T} 599 \mathrm{~A}} \mathrm{~B}-\mathrm{RAF}$ have been modeled starting from the structure of the B-RAF kinase domain [29] using the Modeller 9v8 program [33]. The sequence alignment on this domain with the observed patient mutations was performed with the program Praline [34]. The structural alignment of the mutated sequences with the chosen template (pdb code $1 \mathrm{WUH}$ ) was performed with the program Tcoffee [35]. For each mutant, 200 structures have been generated and the ones with the best DOPE score have been selected for further investigations. The VMD program [36] has been used for graphical representations and for structural analyses.

\section{Transfection of B-RAF alleles in 293 T cells}

$293 \mathrm{~T}$ (Lenti-X $293 \mathrm{~T}$ ) was purchased from Clontech, and maintained in DMEM supplemented with 10\% FBS, 100 units $/ \mathrm{ml}$ Penicillin, and $100 \mathrm{mg} / \mathrm{ml}$ Streptomycin. cDNA fragments of human B-RAF (Genbank accession number: NM_004333) and CRAF (Genbank accession number: NM_002880) were amplified by RT-PGR from human PBMC cDNA and cloned into pMXspuro vector. V600E, T599A, D594A, and G596R B-RAF mutants construct were obtained by site-direct mutagenesis (Agilent Technologies). DLAT insertion B-RAF mutant construct was generated by PCR. The constructs were FLAG-tagged and cloned into pMXs-puro and pMXs-IRES-GFP vectors. The mutations were confirmed by DNA sequencing.

$293 \mathrm{~T}$ was transiently transfected with pMXs-puro, FLAG-BRAF WT, V600E, T599A, 600DLAT, D564A, G596R, or FLAGGRAFvectors as indicated in the figure. Transfection was carried out with jetPEI according to the manufacture's instructions (Polyplus transfections, Inc.).

\section{Generation of stable B-RAF transfectants using retroviral vector}

Retrovirus packaging cell line, Plat-A was purchased from Cell Biolabs, Inc., and maintained in DMEM supplemented with 10\% FBS, 100 units $/ \mathrm{ml}$ Penicillin, and $100 \mathrm{mg} / \mathrm{ml}$ Streptomycin. U937 was kindly donated by Dr. Taams. THP-1 was kindly donated by Dr. Neil. These cell lines were maintained in RPMI supplemented with $10 \%$ FBS, 100 units/ml Penicillin, and $100 \mathrm{mg} / \mathrm{ml}$ Streptomycin (complete medium). Plat-A was transiently transfected with pMXs-IRES-GFP, FLAG-B-RAF WT, V600E, T599A, 600DLAT, D594A, and G596R vectors using jetPEI. Twenty-four hours after transfection, the medium was changed to fresh DMEM, and the cells were cultured for further 24 hours. The virus supernatants were collected and the debris was removed by centrifuge. The supernatants were mixed with DOTAP Liposomal Transfection Reagent (Roche) and added to U937 or THP-1 culture, followed by centrifuge at $30^{\circ} \mathrm{C}$ at $1100 \times \mathrm{g}$ for 2 hours. Forty-eight hours after infection, GFP positive cells were sorted using BD FACSAria (BD Biosciences) and maintained in complete medium. 


\section{Western-Blot analysis}

Twenty-four hours after transfection to $293 \mathrm{~T}$ cells, culture medium was changed to serum-free DMEM and cells starved for 18 hours. Cells were lysed with RIPA buffer $(20 \mathrm{mM}$ Tris-HCl (pH7.4), 150 mM NaCl, 2 mM EDTA, 1\% Nonidet-P 40, 0.1\% Sodium dodecyl sulfate, $0.1 \%$ Sodium deoxycolate, $50 \mathrm{mM}$ Sodium fluoride, $1 \mathrm{mM}$ b-Glycerophosphate, $1 \mathrm{mM}$ Sodium orthovanadate, $1 \mathrm{mM}$ Phenylmethylsulfonyl fluoride, and Protease inhibitor cocktail (Sigma-Aldrich)). For the experiment using THP-1 transfectant, $1 \times 10^{6}$ of growing cells were colllected by centrifuge and lysed in RIPA buffer. The cell lysates were separated on $10 \%$ SDS-PAGE gel and transferred onto nitrocellulose membranes (Bio-Rad). The membrane were blotted with anti-phospho-MEK1/2 mAb (41G9), anti-MEK1/2 mAb (L38C12), anti-phospho-ERK1/2 (D13.14.4E), anti-ERK1/2 $\mathrm{mAb}$ (L34F12) all from Cell Signaling Technology, Inc., and anti-FLAG M2 (Sigma Aldrich). Horseradish peroxidase-coupled secondary antibodies were used to detect the primary antibodies. Signal was revealed by enhanced chemiluminescence (SuperSignal West Pico Chemiluminescent Substrate, Pierce) using a molecular imager Chemidoc ${ }^{\mathrm{TM}}$ XRS+, Biorad. Band intensity was quantified by ImageLab ${ }^{\mathrm{TM}}$ Analysis Software.

\section{References}

1. Guyot-Goubin A, Donadieu J, Barkaoui M, Bellec S, Thomas C, et al. (2008) Descriptive epidemiology of childhood Langerhans cell histiocytosis in France, 2000-2004. Pediatr Blood Cancer 51: 71-75

2. Salotti JA, Nanduri V, Pearce MS, Parker L, Lynn R, et al. (2009) Incidence and clinical features of Langerhans cell histiocytosis in the UK and Ireland. Arch Dis Child 94: 376-380.

3. Stalemark H, Laurencikas E, Karis J, Gavhed D, Fadeel B, et al. (2008) Incidence of Langerhans cell histiocytosis in children: a population-based study. Pediatr Blood Cancer 51: 76-81.

4. Group TFLCHS (1996) A multicentre retrospective survey of Langerhans' cell histiocytosis: 348 cases observed between 1983 and 1993. Arch Dis Child 75: 17-24.

5. Ceci A, de Terlizzi M, Colella R, Loiacono G, Balducci D, et al. (1993) Langerhans cell histiocytosis in childhood: results from the Italian Cooperative AIEOP-CNR-H.X '83 study. Med Pediatr Oncol 21: 259-264.

6. Madrigal-Martinez-Pereda C, Guerrero-Rodriguez V, Guisado-Moya B, Meniz-Garcia C (2009) Langerhans cell histiocytosis: literature review and descriptive analysis of oral manifestations. Med Oral Patol Oral Cir Bucal 14: E222-228.

7. Grois N, Prayer D, Prosch H, Lassmann H (2005) Neuropathology of CNS disease in Langerhans cell histiocytosis. Brain 128: 829-838.

8. Geissmann F, Lepelletier Y, Fraitag S, Valladeau J, Bodemer C, et al. (2001) Differentiation of Langerhans cells in Langerhans cell histiocytosis. Blood 97: 1241-1248.

9. Allen CE, Li L, Peters TL, Leung HC, Yu A, et al. (2010) Cell-specific gene expression in Langerhans cell histiocytosis lesions reveals a distinct profile compared with epidermal Langerhans cells. J Immunol 184: 4557-4567.

10. Egeler RM, van Halteren AG, Hogendoorn PC, Laman JD, Leenen PJ (2010) Langerhans cell histiocytosis: fascinating dynamics of the dendritic cellmacrophage lineage. Immunol Rev 234: 213-232.

11. Annels NE, Da Costa CE, Prins FA, Willemze A, Hogendoorn PC, et al. (2003) Aberrant chemokine receptor expression and chemokine production by Langerhans cells underlies the pathogenesis of Langerhans cell histiocytosis. J Exp Med 197: 1385-1390.

12. Senechal B, Elain G, Jeziorski E, Grondin V, Patey-Mariaud de Serre N, et al. (2007) Expansion of regulatory $\mathrm{T}$ cells in patients with Langerhans cell histiocytosis. PLoS Med 4: e253.

13. da Costa CE, Annels NE, Faaij CM, Forsyth RG, Hogendoorn PC, et al. (2005) Presence of osteoclast-like multinucleated giant cells in the bone and nonostotic lesions of Langerhans cell histiocytosis. J Exp Med 201: 687-693.

14. Gasent Blesa JM, Alberola Candel V, Solano Vercet C, Laforga Canales J, Semler C, et al. (2008) Langerhans cell histiocytosis. Clin Transl Oncol 10: 688-696.

15. Arico M, Nichols K, Whitlock JA, Arceci R, Haupt R, et al. (1999) Familial clustering of Langerhans cell histiocytosis. Br J Haematol 107: 883-888.

16. Weitzman S, Egeler RM (2008) Langerhans cell histiocytosis: update for the pediatrician. Curr Opin Pediatr 20: 23-29.

\section{Quantification of pMEK, pERK, and IL-8 from U937} transfectant by Bio-Plex

For the measurement of IL-8 secretion, $1 \times 104$ of U937 transfectants ware laid in a 96 well plate in 100 microL. After 24 hours, the plate were centrifuged and supernatants were collected. For pMEK and pERK, $1 \times 104$ of U937 were lysed using Bio-Plex Cell Lysis kit. The samples were analyzed according to manufactures instructions.

\section{Statistics}

Unsupervised students t-test on single comparisons was compared to analyse significance. A $\mathrm{P}$ value $<0.05$ was considered significant.

\section{Acknowledgments}

The authors thank patients and their families for participating to the study, Dempsey and his family, and the association Histiocytose france for constant support. We thank Dr Elisa Gomez-Perdigero and Dr Brigitte Senechal for helpful discussions.

\section{Author Contributions}

Conceived and designed the experiments: FG JD TS. Performed the experiments: A. Smith A. Sarde H-CL SM CT. Analyzed the data: FG FF JD. Contributed reagents/materials/analysis tools: GM JFE. Wrote the paper: FG.

17. Willman CL, Busque L, Griffith BB, Favara BE, McClain KL, et al. (1994) Langerhans'-cell histiocytosis (histiocytosis $\mathrm{X}$ )-a clonal proliferative disease. N Engl J Med 331: 154-160.

18. Yu RC, Chu C, Buluwela L, Chu AC (1994) Clonal proliferation of Langerhans cells in Langerhans cell histiocytosis. Lancet 343: 767-768.

19. da Costa CE, Szuhai K, van Eijk R, Hoogeboom M, Sciot R, et al. (2009) No genomic aberrations in Langerhans cell histiocytosis as assessed by diverse molecular technologies. Genes Chromosomes Cancer 48: 239-249.

20. Badalian-Very G, Vergilio JA, Degar BA, Macconaill LE, Brandner B, et al. (2010) Recurrent BRAF mutations in Langerhans cell histiocytosis. Blood.

21. Mercer K, Giblett S, Green S, Lloyd D, DaRocha Dias S, et al. (2005) Expression of endogenous oncogenic V600EB-raf induces proliferation and developmental defects in mice and transformation of primary fibroblasts. Cancer Res 65: 11493-11500.

22. Wellbrock C, Karasarides M, Marais R (2004) The RAF proteins take centre stage. Nat Rev Mol Cell Biol 5: 875-885.

23. Pritchard C, Carragher L, Aldridge V, Giblett S, Jin H, et al. (2007) Mouse models for BRAF-induced cancers. Biochem Soc Trans 35: 1329-1333.

24. Dhomen N, Reis-Filho JS, da Rocha Dias S, Hayward R, Savage K, et al. (2009) Oncogenic Braf induces melanocyte senescence and melanoma in mice. Cancer Cell 15: 294-303.

25. Pollock PM, Harper UL, Hansen KS, Yudt LM, Stark M, et al. (2003) High frequency of BRAF mutations in nevi. Nat Genet 33: 19-20.

26. Dankort D, Curley DP, Cartlidge RA, Nelson B, Karnezis AN, et al. (2009) Braf(V600E) cooperates with Pten loss to induce metastatic melanoma. Nat Genet 41: 544-552.

27. Rolland A, Guyon L, Gill M, Cai YH, Banchereau J, et al. (2005) Increased blood myeloid dendritic cells and dendritic cell-poietins in Langerhans cell histiocytosis. J Immunol 174: 3067-3071.

28. Zhang BH, Guan KL (2000) Activation of B-Raf kinase requires phosphorylation of the conserved residues Thr598 and Ser601. Embo J 19: 5429-5439.

29. Wan PT, Garnett MJ, Roe SM, Lee S, Niculescu-Duvaz D, et al. (2004) Mechanism of activation of the RAF-ERK signaling pathway by oncogenic mutations of B-RAF. Cell 116: 855-867.

30. Kamata T, Hussain J, Giblett S, Hayward R, Marais R, et al. (2010) BRAF inactivation drives aneuploidy by deregulating CRAF. Cancer Res 70: 8475-8486.

31. Heidorn SJ, Milagre C, Whittaker S, Nourry A, Niculescu-Duvas I, et al. (2010) Kinase-dead BRAF and oncogenic RAS cooperate to drive tumor progression through CRAF. Cell 140: 209-221.

32. de Chadarevian JP, Pawel BR (1998) Hereditary Langerhans cell histiocytosis: instances of apparent vertical transmission. Med Pediatr Oncol 31: 559.

33. Eswar N, Eramian D, Webb B, Shen MY, Sali A (2008) Protein structure modeling with MODELLER. Methods Mol Biol 426: 145-159.

34. Simossis VA, Heringa J (2005) PRALINE: a multiple sequence alignment toolbox that integrates homology-extended and secondary structure information. Nucleic Acids Res 33: W289-294. 
35. Notredame C, Higgins DG, Heringa J (2000) T-Coffee: A novel method for fast and accurate multiple sequence alignment. J Mol Biol 302: 205-217.
36. Humphrey W, Dalke A, Schulten K (1996) VMD: visual molecular dynamics. J Mol Graph 14: 33-38, 27-38. 